\title{
SUMBANGAN PAUL RICOEUR DALAM PROSES BERTEOLOGI
}

\section{John C. Simon}

\author{
"He who is unable to reinterpret his past may also be incapable of projecting \\ concretely his interest in emancipation" \\ $\sim$ Paul Ricoeur (1982: 97)
}

\begin{abstract}
In understanding the theologizing process, the foci are not only on the reality, but also on the means or tools to understand the reality. This article intends to explain the means or tools of theologizing process according to Paul Ricoeur. As a process what at stake is not only the method, but also the methodology, namely the thinking process, the interest of the subject and the premises on certain values. The guiding question is what is Ricoeur's theologizing methodology, i.e. his hermeneutics? Through dialogue with many parties, Ricoeur found the methodology of reading reality is started with an affirmation and ended with a critic toward the distortion of reality; this is an affirmative-critical position. However, this methodology is inadequate to comprehend an extremely distorted reality. Hence, the present article offers a reversal move of theologizing process, by prioritizing the critical position toward the distorted reality and following up with the affirmation process by uncovering the element of hope of a good and just life. Ultimately, the theologizing process requires a dialectical methodology of reading the reality, between the critical-affirmative and affirmative-critical positions. The priority of the option is determined by the contextual challenges at hand.
\end{abstract}

Keywords: methodology, the emancipatory hermeneutics, dialogue partners, dialectical, critical-affirmative, affirmative-critical.

\footnotetext{
* Sekolah Tinggi Teologi di Indonesia bagian Timur (STT INTIM) Makassar. Email: tajaksebakal@gmail.com 


\begin{abstract}
Abstrak
Dalam mengerti proses berteologi, perhatian kita tidak hanya tertuju pada realitas, melainkan juga pada sarana atau alat untuk memahami realitas. Tulisan ini bermaksud menjelaskan alat atau sarana dalam proses berteologi menurut Paul Ricoeur untuk digunakan memahami realitas. Sebagai sebuah proses, maka yang mau disentuh tidak hanya soal metode, melainkan metodologi, yaitu proses berpikir, kepentingan yang diusung, dan premis nilai yang dicapai. Pertanyaan yang dijadikan panduan adalah apa metodologi berteologi Ricoeur, yang sering disebut hermeneutik. Melalui dialog dengan banyak mitra, Ricoeur mendapati metodologi membaca realitas dengan pertama-tama bersikap afirmatif baru kemudian kritis terhadap distorsi. Inilah gestur afirmatif-kritis. Namun, metodologi ini tidak memadai untuk membaca konteks yang sudah demikian parah. Dibutuhkan upaya membalik prinsip metodologi Ricoeur dengan pertama-tama mengedepankan upaya kritis terhadap distorsi atas realitas baru kemudian afirmatif untuk menguak pengharapan akan hidup yang baik dan adil. Pada akhirnya, proses berteologi membutuhkan metodologi membaca realitas secara dialektis, antara gestur kritis-afirmatif dan afirmatif-kritis. Mana yang dikedepankan sangat ditentukan oleh tantangan konteks yang dihadapi.
\end{abstract}

Kata-kata kunci: metodologi, hermeneutik emansipatoris, mitra dialog, dialektis, kritisafirmatif, afirmatif-kritis.

\title{
PENDAHULUAN
}

Dalam mengerti proses berteologi, perhatian kita tidak hanya tertuju pada realitas, melainkan juga pada sarana atau alat untuk memahami realitas. Hanya saja, sebaik apa pun sarana atau alat yang dipakai, ia tidak dapat memahami dengan penuh realitas apalagi sampai menggantikan realitas. Realitas pun tidak dapat dibatasi dalam kerangka tertentu yang ada pada sarana atau alat untuk memahaminya. Sebuah perspektif tertentu pun tetap tidak akan memadai. Realitas jauh lebih besar dan kompleks dibandingkan semua sarana atau alat untuk memahaminya.

Sekalipun demikian, sarana atau alat tetap penting dalam upaya memahami realitas yang demikian kaya, elusif, dan tidak pernah akan menjadi fix meaning (Ricoeur, 1995: 39-41). 
Berhadapan dengan realitas, keyakinan yang tumbuh bersifat "terbatas" (contingent, temporer, kontekstual) (Ricoeur, 1985: 217-221) menurut kemampuan kita menangkap dan sangat ditentukan oleh konteks waktu dan tempat tertentu, dan "bisa juga salah" (fallible) (Ricoeur, 1986: 133). Kesadaran ini biasanya kita wujudkan dalam pengertian bahwa pemahaman universal tidak akan pernah tercapai, karena kita begitu terbatas. Pandangan di atas ditopang oleh alam pikir postmodern yang mempromosikan cara pandang skeptis dan nihilis, khususnya terhadap klaimklaim tentang potensi pemikiran dan tindakan manusia (Stiver, 2001: 5-10). Postmodern juga menolak optimisme era modern tentang kemajuan dan pembangunan, termasuk optimisme dapat mencapai pengetahuan universal yang merangkum semua hal.

Berangkat dari latar berpikir di atas, tulisan ini bermaksud menjelaskan alat atau sarana dalam proses berteologi menurut Paul Ricoeur untuk memahami realitas. Tesis saya bahwa sebagai sebuah proses, maka yang mau disasar tidak hanya soal metode berteologi, melainkan metodologi, yaitu proses berpikir, kepentingan yang diusung dan premis nilai yang dicapai. Tulisan ini bermaksud menjawab pertanyaan, apa metodologi berteologi yang ada dalam pemikiran Ricoeur?

Basis berpikir Ricoeur sering disebut dengan hermeneutik. Secara umum hermeneutik dipahami sebagai "seni memahami” (Hardiman, 2015). Di dalam seni memahami terkandung apa yang Ricoeur sebut "nilai paradigmatik" (paradigmatic value) (Ricoeur, 1992: 306). Yang termasuk ke dalam seni memahami adalah memahami realitas di mana manusia hidup dengan posisi mana keprihatinan konteks itu ditanggapi. Dalam tulisan ini akan diperlihatkan bagaimana Ricoeur memanfaatkan pemikiran Gadamer dan Habermas yang masing-masing menyumbang posisi atau gestur teologis tertentu ke dalam pemikiran Ricoeur. Pada akhir pembahasan akan dijelaskan upaya merelevansikan pemikiran Ricoeur secara teologis dialektis, yaitu dengan terus mempertimbangan tantangan konteks yang dihadapi di masa kini.

\section{PAUL RICOEUR DAN MITRA DIALOGNYA}

Hermeneutik Paul Ricoeur sering disebut sebagai hermeneutik emansipatoris, yaitu hermeneutik yang bertugas memahami diri dan bertujuan etis untuk pembebasan. Ricoeur menyinggung tugas emansipasi tersebut ketika mengatakan, "Hermeneutics without a project of liberation is blind, but a project of emancipation without historical experience is empty" (Ricoeur, 1986: 237). Yang berbeda dari hermeneutik lainnya bahwa titik tolak Ricoeur dalam memahami adalah dimulai dari diri sendiri, karena itu hermeneutiknya disebut "hermeneutik tentang diri" (hermeneutics 
of the self) (Ricoeur, 1974: 266). Diri dahulu dipahami dan diemansipasi untuk dibebaskan dari kecenderungannya yang tertutup, egologis, dan hanya mementingkan diri sendiri, menuju diri yang terbuka, dialogis, dan terlibat dalam keprihatinan konteks. Diri yang terbuka itu adalah diri yang hidup baik bersama yang lain dalam institusi-institusi yang adil.

Dalam mengonstruksi pembebasan atas diri, hermeneutik emansipatoris membangun kapasitasnya dalam dialog dengan pemikiran-pemikiran kritis lainnya. Dalam dialog itu, Ricoeur menjelajahi (detour) berbagai macam tanda, simbol, metafora, narasi, dan perjumpaan-perjumpaan yang tersaji melalui pemikiran-pemikiran yang ada, dan kemudian kembali (returning) kepada hermeneutik tentang diri (hermeneutics of the self). Kata Ricoeur "I understand myself only by means of the signs that I give of my own life and that are returned to me via others. All selfknowledge is mediated through signs and works" (Ricoeur, 1991b: 61-62). Tujuannya adalah emansipasi subjek sehingga mempunyai tampilan yang berbeda, berubah menjadi lebih baik dan menata secara baru kehadiran dan tindakannya sebagai subjek yang manusiawi. Kata Ricoeur, "That the interpretation of a text culminates in the self-interpretation of a subject who thenceforth understands himself better, understands himself differently, or simply begins to understand himself" (Ricoeur, 1982: 158).

Mitra dialog Ricoeur untuk proyek pembaruan subjek dapat dikelompokkan menjadi tiga bagian. Pertama, Ricoeur menerima masukan dari tokoh-tokoh sekolah kecurigaan (school of suspicion), yaitu: Marx, Nietzsche, dan Freud, untuk melangkah pada "transformasi subjektivitas". Tujuan dari transformasi itu adalah meruntuhkan ilusi subjek yang absolut, yang eksploitatif dan dominatif. Kedua, Ricoeur pun bermitra dengan Habermas dan Gadamer untuk mempertemukan dua gestur hermeneutik. Yang satu kritis dari tradisi pencerahan, sementara yang lain afirmatif dari tradisi romantisme. Dalam rangka membentuk pemikiran hermeneutiknya, Ricoeur memakai kedua gestur hermeneutik tersebut untuk menegaskan bahasa Alkitab tentang pembebasan, sebuah eksodus (exodus), dan kebangkitan (resurrection). Menurut Ricoeur, kepentingan emansipasi tidak lagi menarik, juga tidak mengandung harapan akan kebebasan, kalau tradisi tentang eksodus dan kebangkitan yang dulu berlaku dihapus dari ingatan umat manusia. Ketiga, Ricoeur berdialog dengan Levinas. Ia menerima kritik atas ontologi klasik yang dilakukan oleh Levinas. Namun, Ricoeur juga kritis terhadap etika asimetris Levinas seraya menjadikan pemikiran Levinas sebagai pintu masuk pada gagasan transformasi ke arah emansipasi diri di dalam institusi-institusi publik yang adil. Lewat usulannya tentang sebuah etika simetris yang saling memberi sikap respek dan rasa hormat dalam kesetaraan, Ricoeur mempertimbangkan pentingnya institusi publik dan sistem demokrasi sebagai konsensus publik di dalam rangka merawat hidup bersama secara adil. 
Motif utama sekaligus irama pernafasan dari seluruh bangunan filsafat Ricoeur adalah detour/return (Ricoeur, 1986: x). Detour/return merupakan kekuatan dari metode hermeneutik Ricoeur, kata Blundell (Blundell, 2010: 8). Namun, menurut saya, detour/return sekaligus merupakan metodologi atau paradigma, yaitu kepentingan hermeneutik Ricoeur dalam merefleksikan kesadaran subjek yang tidak tertutup (seperti yang disangkakan Descartes, Kant, dan Husserl), melainkan terbuka keluar (afirmasi) dan berada bersama yang lain dalam tindakan etis dan adil. Sebagai sebuah paradigma, maka "this long detour is, precisely, suspicion" (Ricoeur, 1974: 244). Sebagai pilihan berada pada jalan kecurigaan, maka tugas emansipasi tidak pernah ditempuh langsung (immediate) atau melalui "jalan pendek" (short route), melainkan ditempuh melalui “jalan panjang” (long detour, long route), yaitu melewati momen "kecurigaan” (suspicion) sampai ilusi subjek yang pongah dan merasa cukup dengan dirinya diruntuhkan. Di sinilah momen emansipatoris Ricoeur mengusung kepentingan sebagai pembebasan atau emansipasi atas subjek untuk terbuka dalam hidup bersama yang lain di dalam institusi-institusi publik yang adil.

Ketiga guru kecurigaan (Marx, Nietzsche, dan Freud), Habermas, Gadamer, dan Levinas menyumbang apa yang disebut Ricoeur "transformasi subjektivitas" yang disebut juga emansipasi subjek. Transformasi diri itu membuat subjek mencapai second nä̈vete, ${ }^{1}$ yaitu diri yang baru, yang cara mencapainya dengan meruntuhkan ilusi subjek yang serba tahu dan pongah yang tampil dalam tindakan eksploitatif dan dominatif. Melalui kritik atas ilusi subjek tergambar jelas apa yang Ricoeur sendiri sebut tentang pemikirannya sebagai "filsafat antropologi”, yaitu pemikiran yang berisi mengenai gambaran dunia baru dengan visi tentang manusia yang lebih baik dan adil (Ricoeur, 1974: 100). Melalui ketiga guru kecurigaan (Marx, Nietzsche, dan Freud), Habermas, Gadamer, dan Levinas, tersusun pula tugas hermeneutik kritis emansipatoris, yaitu menguak kepentingan yang melandasi semua usaha pengetahuan — entah basisnya pada ekonomi (Marx), psikologi (Freud), antropologi (Nietzsche), kritik ideologi (Habermas), hermeneutik (Gadamer), dan etika (Levinas) — bagi terbitnya emansipasi ruang publik. Kesemua sumbangan pemikiran dari mitra-mitra dialog Ricoeur menjadi alat analisis bagi teori sosial kritis, di mana "task for a critical social theory is to argue for a conception of justice that challenges institutionalized domination and oppression while affirming a heterogeneous public and group differences" (Kaplan, 2003: 154). Lantas terciptalah cara baru melihat diri dan dunia yang tidak lain merupakan cara baru berada di dalam dunia (being-in-the-world) yang adil dan manusiawi.

Dalam memahami realitas, Paul Ricoeur menerangkan bahwa hermeneutik dipahami sebagai refleksi yang dimediasi. Hermeneutik menjelaskan bahwa tidak ada pemahaman diri tanpa diperantarai oleh tanda, simbol, teks, termasuk kehadiran orang lain. Pemahaman diri tidak akan 
terjadi kecuali melalui jalan panjang (long detour): "I give of my own life and that are returned to me via others" (Ricoeur, 1991b: 61). Pemahaman diri atau disebut juga refleksi dipahami sebagai ajakan kembali ke diri sendiri, yakni "what the Gospel says of the soul: to be saved, it must be lost [...] the self (le moi) must be lost in order to find the 'I' (le je)" (Ricoeur, 1974: 20). Lahirlah diri yang baru (second naïvete) (Ricoeur, 1970: 28, 496), yakni diri dalam tanggung jawab moral bersama dan dengan yang lain di dalam institusi yang adil. Diri yang baru itu juga tumbuh karena bermekarannya apa yang Ricoeur sebut phronesis, yaitu kebijaksanaan praktis dalam kehidupan konkret. Aku tidak akan mencapai kepenuhan diri tanpa keterlibatan dalam hidup nyata. Pengalaman puncak pencapaian diri yang baru hanya melalui relasi-relasi dengan yang lain. Kita dapat mencapai pemahaman diri kita melalui yang lain (oneself as another), yaitu berkat segala kemampuan diri yang selalu dimengerti sebagai diri yang terbuka dan terbagi untuk yang lain.

\section{MENIMBANG SUMBANGAN GADAMER DAN HABERMAS}

Seperti disebut di atas, salah satu mitra dialog Ricoeur adalah Gadamer dan Habermas. HansGeorg Gadamer (1900-2002) mewakili tradisi hermeneutik, sedangkan Jürgen Habermas (1929-...) mewakili teori kritis atau kritik ideologi. Ricoeur mempertimbangkan sumbangan Gadamer dan Habermas dalam pemikirannya dengan mengatakan pernyataan penting bahwa hermeneutik dan kritik ideologi bisa saling menopang. Kata Ricoeur, "That of hermeneutics and that of the critique of ideology, are interpenetrating" (Ricoeur, 1982: 95).

Secara deskriptif, terdapat empat perbedaan antara hermeneutik dan kritik ideologi (Ricoeur, 1982: 79-87). Pertama, Gadamer merehabilitasi prasangka, tradisi, dan otoritas dengan mengaitkannya dengan pemahaman Heidegger tentang "proyek keterlemparan" (thrown project) di mana Dasein hanya menerima tanpa pernah bisa mengkritik, sementara Habermas mengembangkan konsep kepentingan yang berasal dari tradisi Marxis atau pencerahan yang gesturnya pembebasan. Di tangan Ricoeur, hermeneutik mengusung tugas ganda, yaitu mengafirmasi tradisi dan seluruh artifak sejarah sebagai bagian yang melekat pada diri (apropriasi), dan sekaligus mengkritiknya agar terbebas dari kepentingan ideologis menindas (distansiasi). Kedua, Gadamer menggunakan ilmu-ilmu kemanusiaan untuk menginterpretasi kembali dan mengatasi penjarakan dari tradisi, sementara Habermas menggunakan ilmu-ilmu sosial kritis dengan tujuan untuk membuka kemungkinan-kemungkinan emansipasi melalui refleksi kritis atas bahaya reifikasi (pembendaan) dan alienasi ideologis (Hardiman, 1992/1993: 42-61 [46, c.k. 5]; tentang reifikasi lih. Ricoeur, 
1982: 96-97; 1986: 235). Di tangan Ricoeur, kedua pemikiran diterima menjadi studi interdisipliner, yang karena berdialog dengan banyak ilmu, kebenaran dapat didekati secara lebih baik, utuh, dan holistik, serta muaranya menghindari dari pengetahuan yang diterima secara tidak kritis. Ketiga, Gadamer menerima kesalahpahaman sebagai rintangan menuju pemahaman, sementara bagi Habermas setiap rintangan adalah ideologi atau komunikasi yang didistorsi secara sistematik yang memunculkan konsensus palsu dan pseudo-komunikasi. Di tangan Ricoeur, hermeneutik bukan hanya memahami pemahaman, tetapi menjadi proses memahami kesalahpahaman. Tujuan memahami kesalahpahaman adalah mempertahankan sikap kritis pada aneka distorsi yang barangkali bersembunyi di belakang bahasa, termasuk bahasa keagamaan. Keempat, Gadamer mendasarkan tugas hermeneutik pada ontologi bahasa sebagai kesadaran sejarah yang given, sementara Habermas justru mengaitkan teori komunikatif dengan prinsip komunikasi takterbelenggu. Di tangan Ricoeur, belokan bahasa (linguistic turn) menjadi makin jelas. Melalui bahasa kepentingan emansipasi disampaikan, sekaligus kepentingan membelenggu dipraktikkan. Karena itu kita tidak boleh mudah begitu saja menerima sebuah argumen yang dapat membawa pada dominasi dan kepatuhan buta. Melalui bahasa, segala sesuatu tidak bebas kritik. Demikian sebaliknya, sudah paham padahal belum melakukan apa-apa.

Bila disederhanakan maka perbedaan keduanya adalah antara kerendahan hati hermeneutik dan daya penentang kritik ideologi terhadap semua bentuk kesadaran palsu. Dalam bahasa Kaplan perbedaan itu adalah antara "the humility of philosophical hermeneutics and the defiance of the critique of ideology" (Kaplan, 2003: 38). Hermeneutik menekankan keterbatasan dan kondisikondisi historis di mana kita menjadi bagiannya, sementara kritik ideologi menentang distorsidistorsi tersembunyi dan sistematik dari pemahaman diri tentang komunitas ideal dalam komunikasi tak terbelenggu.

Dengan semua perbedaan yang ada, pertanyaan yang muncul adalah: Apakah bisa membuat hermeneutik yang dapat melakukan kritik? Atau, dengan kata lain: Bisakah kritik lahir dalam hermeneutic? (Ricoeur, 1982: 88; 1991b: 295). Ricoeur menawarkan empat suplemen bagi hermeneutik yang dapat menjalankan fungsi kritik ideologi (Ricoeur, 1982: 91-95; 1991b: 298-301). Pertama, pengakuan pada jarak (distance) sebagai momen penting untuk membuka kemungkinan bagi kritik di dalam hermeneutik. Menurut Ricoeur, kita tidak pernah menjadi bagian dari tradisi atau cakrawala yang dihidupi selama kita tidak dapat merefleksikan batas-batas pemahaman kita sendiri. Bahkan kita tidak akan pernah mencapai emansipasi di masa depan, jika kita tidak bisa mengeritik masa lalu. Keberadaan kita selalu di antarai oleh masa lalu dan masa depan. Dan proyeksi masa depan yang baik, antara lain dibangunkan oleh cara kita melihat dan membuat jarak dengan masa 
lalu. Kedua, mengatasi dikotomi antara penjelasan (explanation) dan pemahaman (understanding) untuk menyatukan keduanya secara dialektis dengan tujuan menghitung kemampuan melakukan kritik, utamanya kritik terhadap ilusi subjek yang absolut model cogito Descartes dan solipsistis Husserl (Ricoeur, 1967: 91-92). Kesatuan itulah yang melahirkan pemahaman, dan pemahaman sekali lagi tidak pernah langsung, melainkan memerlukan mediasi lewat kehadiran yang lain. Karena itu tiba pada pemahaman sama dengan kerendahan hati. Tanpa kerendahan hati, maka yang ada hanyalah pengentalan ilusi subjek. Hingga, saya dan yang lain berhadap-hadapan dalam banyak praktik kekerasan dan ketidakadilan. Sesuatu yang tidak diharapkan tentunya. Ketiga, pengakuan pada dimensi referensial (mediasi) yang mengandung kekuatan yang potensial bagi imajinasi tentang hidup yang lebih baik di dalam institusi-institusi yang adil (Ricoeur, 1992: 172, 180). Bagi Ricoeur, perluasan teori interpretasi ke wilayah tindakan manusia menjadi mungkin karena tindakan itu sendiri merupakan rujukan dari berbagai teks. Dengan kata lain, tidak ada tindakan yang berdiri sendiri tanpa sebuah referensi. Kesadaran ini membuka ruang relasi dan interdependensi yang datang dari subjek yang sama-sama belajar menjadi baik. Dengan meminjam mimesis-nya Aristoteles, Ricoeur mengatakan bahwa tindakan manusia adalah kreativitas tiruan (creative imitation) manusia (Ricoeur, 1982: 16; 1991b: 138; Dornisch, 1989: 308-318). Dalam setiap imajinasi kreatif terdapat mimesis tentang sebuah tindakan untuk hidup yang lebih baik. Bagi Ricoeur, setiap mimesis hanya datang dari subjek yang mengakui kehadiran yang lain, dan menerima dengan tangan terbuka bahwa yang lain termasuk ia yang membentuk identitasku. Bersamaan itu, keterbukaan ini sekaligus pengakuan bahwa liyan selalu merupakan misteri yang menunjuk pada Liyan yang lebih besar, Liyan yang akan datang, Liyan eskhatologis, yaitu Liyan pengharapan akan hidup yang lebih baik. Keempat, terdapat hubungan antara transformasi subjektivitas dan kritik atas kesadaran palsu. Di sini setiap interpretasi mensyaratkan interpretasi diri. Dalam proses menginterpretasi itu, maka "saya tidak lagi menyadari diri saya" (I unrealise myself). Interpretasi memperkenalkan kepada saya "ragam ego imajinatif'.2 Ragam ego imajinatif inilah, menurut Ricoeur, yang membuka kemungkinan bagi "kritik atas ilusi subjek", sebab aku bukanlah keberadaan yang sendirian, egologis, dan tertutup (solipsistis) melainkan berada dengan yang lain, di antara yang lain-yang lain dan terbuka melalui relasi-relasi dialogis yang makin meluas. Bahkan melalui dialog terbuka — karena aku adalah diri yang pecah atau retakilusi subjek yang tertutup diperhadapkan pada kritik terus-menerus hingga akhirnya diruntuhkan. Kritik itu semacam pemastian bahwa aku tidak akan pernah menjadi totalitas, tetapi selalu terbagi, retak, dan terpecah, agar liyan itu dimungkinkan masuk, membuat tidurku terjaga atau mengusik segala bentuk kemapananku. Di sinilah yang lain diterima dengan sikap keramahan dan diakui ikut menentukan keberadaan diriku. Yang lain adalah pembentuk identitasku. 
Konsep-konsep inilah yang tidak berkembang di dalam hermeneutik tradisi Gadamer karena terlalu cepat memperkenalkan "pendakuan" (aneignung, appropriation) yang tujuannya untuk menampik penjarakan yang dianggap mengasingkan. Ketika penjarakan ditampik, maka kritik pun tidak muncul dan itu artinya subjek absolut tetap menjadi masalah. Karena itulah, kritik ideologi harus ditempatkan sebagai sejawat dari kritik atas ilusi subjek. Begitu pula kritik atas kesadaran palsu bukan pasangan yang terpisah dari hermeneutik. Hanya dengan cara begitulah refleksi diri membuka pada refleksi kritis yang penting bagi emansipasi subjek. Sehingga setiap interpretasi atas ilusi subjek dengan cara yang sama merupakan kritik ideologi. Tujuan yang mau dicapai dari sebuah kritik adalah bersifat konstruktif, yakni melahirkan seorang individu yang terbuka menerima kehadiran yang lain dan terbuka pula berdialog dalam kesetaraan untuk membangun kehidupan yang lebih baik dan adil. Sehingga proses pembentukan diri sesungguhnya bergerak dari konstruksi atas diri menuju konfrontasi atas diri dan kembali ke konstruksi atas diri secara baru.

Perdebatan antara Gadamer dan Habermas juga berpusat pada apa makna dan fungsi tradisi (Ricoeur, 1988: 227). Jika Gadamer memandang tradisi secara positif sebagai sumber kesadaran historis untuk mencapai pemahaman, Habermas berbeda. Ia memandang tradisi dengan mata kecurigaan sebagai sumber distorsi-distorsi sistematik yang melanggengkan dominasi. Kaplan menggambarkan persoalannya demikian:

\footnotetext{
"Habermas claims that Gadamer rightly ties understanding to historical understanding conciousness but offers no possibility of transcendence in order to evaluate our historically effected consciousness. If there is no transcendental perspective on history, then there is no way to recognize if my tradition is ideologically distorted. If there is no way to recognize ideological distortions, then there is no way to criticize the domination and injustice tradition may conceal" (Kaplan, 2003: 41).
}

Dari analisis Kaplan itu, Gadamer sesungguhnya menyetujui Habermas bahwa bahasa bukan hanya tempat rasionalitas dan konsensus tetapi juga tempat pemaksaan dan dominasi. Jika begitu, maka "hermeneutics is already a critique of conciousness and communication" (Ricoeur, 1991b: 294). Di tangan Ricoeur, perdebatan Gadamer dan Habermas dibaca secara dialektis. Ia lalu mengungkap kedua fungsi itu dalam satu kesatuan makna: "The gestur of hermeneutics is a humble one of acknowledging the historical conditions to which all human understanding is subsumed in the reign of finitude; that of the critique of ideology is a proud gesture of defiance directed against the distortions of human communication" (Ricoeur, 1982: 87). Dengan kedua gestur hermeneutik, yang satu rendah hati dan yang lain kritis, tujuan yang disasar adalah samasama menentang "kesadaran palsu", yaitu distorsi komunikasi manusia yang menyembunyikan dominasi dan kekerasan. Bagi Ricoeur, hermeneutik dan kritik ideologi adalah pasangan dan bisa 
saling menopang untuk mengemansipasi wilayah privat, yaitu meruntuhkan subjek absolut, dan wilayah publik, yaitu dari pembudayaan dominasi dan kekerasan.

Perdebatan antara Habermas dan Gadamer merupakan dua sikap fundamental filsafat, yaitu: (1) ketundukan pada keterbatasan (afirmatif), dan (2) perlawanan terhadap dominasi (kritis-konfrontatif) (Ricoeur, 1982: 33-34, 87; 1991b: 294). Ricoeur menerima keduanya, baik rehabilitasi tradisi dan pemahaman historis dalam kasus hermeneutik tradisi Gadamer, dan kecurigaan terhadap penyimpangan institusi melalui bahasa dan kekuasaan dalam kasus kritik ideologi Habermas.

Selain itu, gagasan Gadamer tentang prasangka juga penting. ${ }^{3}$ Sebab, prasangka yang sudah mendarah daging akan sulit dikritik dan justru akan menjadi ideologi. Atas hal ini Ricoeur lalu membuat "jalan tengah" antara penerimaan akan tradisi (Gadamer) dan kecurigaan (Habermas) atasnya. Jalan tengah ini dibangun oleh jalan pe-nalar-an. Kata Ricoeur: "makes its plea before the tribunal of reason" (Ricoeur, 1988: 227). Dalam nalar yang demikian, kita seharusnya menerima klaim kebenaran tradisi atau otoritas sebagai benar menurut anggapan tertentu dan temporal, sampai ada argumen lebih baik yang menunjukkan sebaliknya dan kita pun bersedia mengubah pandangan yang terbukti keliru tersebut. Dalam pengalaman hermeneutik, momen keterbukaan dan penerimaan mendahului momen kritik dan penjelasan. Kita duluan mengafirmasi hidup, sebelum kita melakukan kritik atas hidup. Sejarah menghampiri kita terlebih dahulu, sebelum kita memberikan kritik atasnya. Kata Ricoeur:

\footnotetext{
"That confident reception by which we respond, in an initial move preceding all criticism, to any proposition of meaning, any claim to truth, because we are never at the beginning of the process of truth and because we belong, before any critical gesture, to a domain of presumed truth" (Ricoeur, 1988: 225).
}

Dengan jalan pe-nalar-an tersebut, maka sahnya sebuah otoritas tradisi bahkan ideologi hanya terjadi dalam proses komunikasi dan argumentasi diskursif di antara interlokusioner yang saling berdialog (Ricoeur, 1991b: 79, 302; 1982: 95). Dalam dialog tidak ada argumen yang bebas dari kritik. Semua argumen, termasuk yang berasal dari agama dan dianggap sakral sekalipun, terbuka pada proses diskusi dan kritik. Di luar itu hanyalah komunikasi yang dipaksakan dan penuh dominasi. Dari sini pun menjadi jelas bahwa posisi Ricoeur dalam menjembatani antara apa yang sekarang terjadi (misalnya: kondisi ketidakadilan) dan apa yang seharusnya (keadilan) adalah model kebenaran yang diasumsikan tunduk pada keabsahan rasional. Sehingga hermeneutiknya pun tergolong hermeneutik kesadaran (hermeneutic consciousness) (Ricoeur, 1982: 432; 1974: 108-120 [119-120], 260, 324). Namun, berbeda dengan kesadaran yang berpusat pada subjek absolut, yang dalam filsafat Barat warisan Cartesian bersifat egologis, maka kesadaran yang Ricoeur maksud 
adalah "kesadaran tentang hidup secara baik" (consciousness of life as well) bersama yang lain dalam tindakan yang adil (Ricoeur, 1992: 186). Dari sini pula menjadi jelas tugas refleksi filsafat yang dimaksud Ricoeur, yakni: "in the reinterpretation of cultural heritages received from the past and the interest in the futuristic projections of a liberated humanity" (Ricoeur, 1982: 100).

Ricoeur sepakat dengan Habermas dan Gadamer bahwa setiap kritik atas tradisi dan otoritas dimediasi oleh cita-cita regulatif akan komunikasi yang tak terbatas dan bebas dominasi (Habermas), yang, pada gilirannya, sikap kritis tetap ditempatkan secara historis dengan maksud agar dapat diterapkan dalam konteks tertentu (Gadamer) (Ricoeur, 1982: 74, 97; 1991b: 281, 303). Di sini kesadaran sejarah penting karena arah keprihatinan yang dikritisi itu tertuju kepada sejarah manusia konkret dan menuju emansipasi yang konkret pula. Seperti Habermas, Ricoeur lebih suka menekankan dasar keabsahan komunikasi agar kita mampu mencapai pemahaman yang benar dalam komunikasi. Dasarnya bahwa tidak ada komunikasi yang dipaksakan, karena itu semua argumen layak untuk didengar. Tidak ada juga argumen yang bebas kritik. Dalam komunikasi diandaikan sebuah kemampuan untuk menjelaskan diri sendiri dengan apa yang kita katakan sebaik mungkin dan dapat melahirkan tanggung jawab dalam tindakan. Ricoeur setuju dengan pendapat Habermas bahwa "the goal of coming to an understanding is to bring about an agreement that terminates in the intersubjective mutuality of reciprocal understanding, shared knowledge, mutual trust, and accord with one another" (Kaplan, 2003: 44). Yang paling penting bahwa Ricoeur menggemakan mediasinya perihal perdebatan Habermas dan Gadamer itu mengerucut pada kearifan praktis (practical wisdom) (Ricoeur, 1986: 314), yang berisi keyakinan yang dihormati, argumen yang baik dan hasrat untuk hidup baik bersama dan demi orang lain dalam institusi-institusi yang adil.

Diskusi antara hermeneutik dan kritik ideologi sesungguhnya menghantar percakapan ini pada fungsi ideologi dalam hubungannya dengan membaca konteks atau realitas, termasuk itu tradisi dan otoritas. Menurut Ricoeur, fungsi ideologi adalah pertama-tama "to pattern, to consilidate, to provide order to the course of action" (Ricoeur, 1991b: 318). Fungsi primer ini juga disebut "the integrative function of ideology, the function of preserving an identity". Fungsi primer ini merupakan sumbangan Gadamer dalam pemikiran Ricoeur. Setelah fungsi primer ini kita mendapati fungsi kedua, yaitu "ideology as distortion and as the legitimation of a system of order or power" (Ricoeur, 1986: 258). Fungsi sekunder ini merupakan sumbangan Habermas dalam pemikiran Ricoeur. Jelaslah bahwa bagi Ricoeur fungsi primer ideologi adalah integratif dan fungsi sekundernya adalah distortif. Bila kedua fungsi tersebut digunakan, maka membaca realitas secara metodologis berarti memulai dengan sikap afirmatif-integratif baru kemudian kritiskonfrontatif terhadap distorsi atas realitas. 


\section{DARI FUNGSI KRITIS KE FUNGSI INTEGRATIF: MEMBALIK PRINSIP}

Konstruksi Ricoeur tentang ideologi sangat positif karena sisi yang ditekankan adalah fungsi ideologi sebagai identitas dan integrasi sosial. Inilah fungsi primer ideologi, yang mendahului fungsi sekundernya yang bersifat kritis-konfrontatif terhadap semua distorsi, praktik kekerasan, ketidakadilan, dan kesadaran palsu. Persoalannya bahwa posisi hermeneutik Ricoeur yang afirmatif ini sekaligus menjadi titik lemahnya dalam membaca konteks yang sudah sangat patologis akibat globalisasi imperialisme yang menyebabkan kemiskinan, kerusakan lingkungan, dan ketidakadilan yang menaikkan tensi radikalisme dan terorisme. Ricoeur "terlalu percaya diri" (over-confident), bahkan terlalu berpikir positif terhadap realitas sehingga pemikirannya tidak relevan dengan realitas yang sebenarnya sudah demikian patologis dengan segala relasi-relasinya yang kooptatif, dominatif, dan tidak adil (Simon, 2016).

Saya mengusulkan bahwa dalam rancang bangun metodologi berteologi kontekstual, maka menafsir kenyataan yang sudah distortif penuh praktik kekerasan dan ketidakadilan itu berarti memperlihatkan tugas hermeneutik yang bertolak dari tahapan kritis (hermeneutics of suspicion) menuju ke tahapan afirmasi (hermeneutics of affirmation) (Simon, 2016). Dengan membalik prinsip metodologis, maka kita bergerak dengan pisau kecurigaan (suspicion) terlebih dahulu untuk membuka selubung kepentingan (debunking) yang bermain di dalam relasi ideologi yang dominatif, menindas, dan tidak adil, baru dari sana kita mengafirmasi dan mengintegrasikan sebuah mimpi dan pengharapan untuk hidup baik bersama orang lain. Inilah dimensi eskatologis dari hermeneutik Ricoeur, bahwa relasi dengan liyan menunjuk kepada "sesuatu” yang lebih besar, yaitu Liyan yang akan datang, Liyan dari masa depan. Secara teologis, Ricoeur menyebutnya Kerajaan Allah. Ia adalah penggagas paradigma hermeneutik Kerajaan Allah dengan mengusung kepentingan keadilan sebagai premis nilai yang diperjuangkannya (Ricoeur: 1995, 44; 1991b: 9598 [96]). Tugas menghadirkan Kerajaan Allah ini pertama-tama adalah sebuah tugas hermeneutik yang kritis dan secara etis mengusahakan keadilan, perdamaian, dan keutuhan ciptaan. Inilah yang juga dimaksudkan Ricoeur sebagai "solidaritas global” (planetary solidarity) (Ricoeur, 1994: 2), sebagai solidaritas adil terhadap mereka yang yang lemah, miskin, tak berdaya, termasuk terhadap alam, agar tercipta keadilan yang berdampak bagi keutuhan ciptaan. Lebih lanjut, bagaimana fungsi kritis dan afirmatif ini bekerja?

Berbeda dengan Habermas yang mengatakan bahwa ideologi dominan saat ini adalah ilmu pengetahuan dan teknologi, maka menurut Ricoeur, ideologi dominatif saat ini adalah homo oeconomicus (Ricoeur, 1966: 116; 1982: 97). Tampilan paling menyolok dari spirit homo 
oeconomicus adalah ekspansi, dominasi, dan penindasan di bidang ekonomi. Sejalan dengan dominasi ekonomi, maka perlakuan terhadap ekologi juga tak kalah ganasnya diperas dan dieksploitasi melampaui batas regenerasinya. Sekarang imperialisme modern pun digerakkan oleh roh yang sama demi untuk tetap survive sekalipun itu dilakukan dengan menebar teror dan peperangan di mana-mana.

Bertahannya spirit dominasi ini dapat pula dijelaskan lewat perspektif sejarah. Ricoeur sendiri memang memaksudkan emansipasi tidak terpisah dari kesadaran sejarah, yaitu sejarah penindasan dan ketidakadilan dari manusia-manusia yang kalah. Tentang sejarah Ricoeur berpendapat: "History would be economic history, history made by the homo oeconomicus - and not political history, history made by the man of prey" (Ricoeur, 1966: 119). Dengan logika hidup yang saling memangsa untuk memperbesar keuntungan sendiri, maka tercipta apa yang Ricoeur sebut catastrophic situation (Ricoeur, 1966: 121), yaitu situasi ketimpangan antara yang menang dan yang kalah, hingga menciptakan kematian pada hidup bersama karena manusia memangsa manusia lainnya. Catastrophic situation juga berarti situasi di mana bahaya besar berupa ketidakadilan, kemiskinan, dan kerusakan ekologi sudah menyatu menjadi daya kematian bagi kehidupan bersama.

Seperti jelas di atas, upaya kritis Ricoeur dengan mengambil jalan pe-nalar-an, juga didasarkan pada kesadaran bahwa ideologi modern berupa homo oeconomicus telah bermain di wilayah proses rasionalisasi yang bermaksud menjinakkan wilayah tindakan instrumental dan memanipulasi praksis, yaitu "kehidupan yang baik" (good life) (Ricoeur, 1982: 99; 1991b: 305; 1992: 172, 180, 239). Praksis tertekan atau tergencet karena terpisah secara diametral dengan teori atau refleksi. Teori pun memanipulasi realitas atau praksis hidup konkret sehingga menciptakan tindakan-tindakan tuna-etik dan tuna-moral. Homo oeconomicus sebagai ideologi pun menjadi alat legitimasi kekuasaan yang kuat atas yang lemah sehingga praksis hidup yang baik dan adil tidak pernah muncul, tersembunyi oleh aneka kepentingan yang menindas. Dalam konteks inilah, praksis keadilan membutuhkan topongan pisau analisis metodologis berupa sarana atau alat memahami realitas secara kritis.

Konteks homo oeconomicus di balik globalisasi imperialisme yang patologis membutuhkan metodologi (paradigma) menganalisis yang baru, yaitu dengan membalik prinsip metodologis afirmatif-kritis menurut Ricoeur menjadi kritis-afirmatif. ${ }^{4}$ Dalam konteks globalisasi imperialisme yang demikian menggurita dengan praktik kekerasan dan dominasi yang kuat atas yang lemah, hermeneutik kritis emansipatoris pertama-tama akan melihat persoalan ideologi sebagai distorsi atas realitas (fungsi sekunder), karena praktik dominasi, kekerasan, dan persoalan ketidakadilan 
telah menggurita di mana-mana. Di sini fungsi kritis tidak tergantikan oleh fungsi afirmatif atau integratif. Secara metodologis, kritik atas distorsi realitas ketidakadilan adalah langkah pertama yang dilakukan, baru kemudian mengafirmasi sebuah harapan tentang kehidupan yang lebih baik. Dari melihat akar persoalan sosial secara kritis itu kita bergerak menuju gagasan afirmatifintegratif-transformatif untuk mengubah realitas menjadi lebih baik dan lebih adil.

Mengedepankan cara membaca kritis atas realitas yang kental dengan dominasi, ketidakadilan, dan distorsi (fungsi sekunder) justru menolong kita untuk punya seperangkat analisis sosial kritis dengan paradigma kecurigaan pada selubung kepentingan (debunking) yang bermain di dalam ideologi yang dipakai dan menyembunyikan kepentingan yang menyebabkan ketidakadilan. Tanpa pertama-tama mengedepankan sikap "kecurigaan hermeneutis" (hermeneutics of suspicion), menurut saya, kita sulit menemukan perspektif pengharapan tentang hidup yang lebih baik dan adil di masa depan. Pendekatan apresiatif atas kehidupan yang lebih baik merupakan hasil dari daya kritis terhadap kekuatan-kekuatan anti kehidupan yang hadir dalam aneka wajah. Jalan ini, menurut saya, merupakan isi dari metodologi atau paradigma berteologi yang diinspirasi oleh hermeneutik Ricoeur untuk membaca konteks masa kini.

\section{PENUTUP: SEBUAH PENDEKATAN DIALEKTIS}

Pertanyaan yang penting diajukan adalah apakah paradigma afirmatif-kritis dan kritis-afirmatif selalu ada dalam ketegangan yang tak terjembatani? Bisakah keduanya berfungsi dialektis? Dalam membaca realitas, tugas kritis dan afirmatif atau afirmatif dan kritis sesungguhnya sudah disadari Ricoeur dan bekerja secara dialektis (Ricoeur, 1986: 258). Sikap kritis-konfrontatif tidak selamanya dan satu-satunya menjadi pilihan sikap dalam memahami konteks. Sikap ini juga tidak dapat bekerja terus-menerus karena tidak ada orang yang dapat tahan dengan kritik yang bertubitubi. Sikap kritis perlu dibarengi dengan tugas afirmatif dan apresiatif terhadap konteks. Caranya dengan memberi apresiasi terhadap kehidupan yang ada pada konteks sebagai sesuatu yang darinya kita dapat belajar. Sikap yang terbuka adalah bahwa yang lain mempunyai kebenaran dan darinya dapat diperoleh nilai yang bisa dipelajari. Inilah sikap apresiatif atas konteks yang dihadapi.

Dalam pengalaman orang Indonesia memahami realitas, sikap yang pertama-tama dikedepankan adalah konfrontatif. Konteks dan seluruh isi yang hidup di dalamnya ditanggapi dengan sikap konfrontatif, mencari perbedaan hingga memusuhi. Salah satu cara konfrontatif itu adalah metode explaining away terhadap konteks kemajemukan agama dan budaya, dengan 
menjelaskannya untuk maksud membabat habis dan menempatkan agama dan budaya sendiri di atas semua yang lain. Sikap konfrontatif sering kali tidak jauh dari sikap superioritas atas yang lain dengan membangun ketertutupan disertai seperangkat klaim kebenaran atas yang lain. Karena itu sangat bisa dimengerti jika Gerrit Singgih (Singgih, 2004b: 176; 2004a: 171) misalnya, kemudian menyarankan agar orang-orang Kristen di Indonesia yang selama ini diajari oleh kaum misionaris kolonial mengonfrontasi realitas dan menganggapnya sebagai berasal dari yang jahat atau setan, mau mengubah pendekatannya dengan mengedepankan sikap apresiatif dan konfirmatif.

Seperti sudah dicatat di atas bahwa sikap konfrontatif sering kali dimaknai sempit sebagai menghakimi bahkan menolak unsur-unsur baik yang ada dalam realitas. Sikap menilai sebetulnya merupakan salah satu sikap hermeneutis (Ricoeur, 1982: 279), namun menjadi masalah ketika jatuh dalam sikap menghakimi dalam klaim kebenaran yang tertutup. Yang paling mudah adalah terhadap konteks kemajemukan agama dan budaya. Agama-agama dan budaya-budaya lain dianggap sesat, berasal dari setan dan diperlakukan sebagai musuh yang layak diperangi. Yang sering dilupakan adalah sikap positif dari pendekatan konfrontatif, yaitu kritis, yang bermaksud membarui, mentransformasi, dan menambahkan yang tidak ada di dalam yang sudah ada. Melalui tatapan kritis terhadap konteks, kita dapat keluar dari perangkap ideologis yang sering kali sarat dominasi dan praktik kekerasan. Kesadaran akan fakta ideologis ini akan memberi daya yang besar bagi gerakan-gerakan emansipasi yang diusahakan.

Sementara itu sikap yang lain adalah afirmatif. Sikap ini sejajar dengan sikap konfirmatif, yang merupakan usaha membenarkan dan mengiakan segala sesuatu yang baik dan benar dalam kebudayaan-kebudayaan atau agama-agama lain. Terhadap yang lain yang berbeda kita pun dapat memperoleh wawasan (insight) untuk dipelajari bagi transformasi subjektivitas. Kedua sikap metodis ini, kritis dan afirmatif, sesungguhnya bukan sikap yang terpisah diametral satu dengan yang lain. Keduanya secara dialektis berjalan bersama sebagai alat atau sarana membaca realitas. Mana yang didahulukan sangat ditentukan oleh tantangan konteks yang dihadapi. Menurut saya, konteks hari ini yang ditandai oleh roh homo oeconomicus melalui sistem globalisasi ekonomi yang tidak adil dan penuh kerakusan, membutuhkan metodologi berteologi untuk membaca konteks dengan mendahulukan pendekatan kritis.

Akhirnya, dengan menelusuri pemikiran hermeneutik Paul Ricoeur didapati kerangka metodologi berteologi untuk membaca konteks, yaitu kritis-afirmatif dan afirmatif-kritis, yang keduanya secara dialektis berjalan bersama-sama. Realitas tidak hanya dikritisi, melainkan juga diafirmasi, sebaliknya, realitas tidak hanya diafirmasi, melainkan juga dikritisi. Ketegangan dialektis ini sebaiknya dipertahankan untuk menyasar tujuan ganda teologi hermeneutik, yakni 
meruntuhkan ilusi subjek yang absolut dan mengungkap sebuah pengharapan tentang hidup bersama secara baik dan adil. Yang pertama bermakna emansipasi ruang privat, dan yang kedua bermakna emansipasi ruang publik. Dialektika antara tugas emansipasi ruang privat dan ruang publik merupakan upaya bermetodologi-teologi yang diinspirasi oleh pemikiran Paul Ricoeur.

\section{Catatan}

${ }^{1}$ Ricoeur menggunakan istilah ini pertama kali (a term Ricoeur first uses in) di dalam bukunya, The Symbolism of Evil (Ricoeur, 1969: 351). Gagasan Ricoeur ini diinspirasi oleh pemikiran Karl Barth (lih. Ricoeur, 1991a: 473).

2 Teks Inggris: "introduces me to imaginative variations of the ego" (lih. Ricoeur, 1982: 94).

${ }^{3}$ Kata Ricoeur: "Gadamer inevitably turned hermeneutic philosophy towards the rehabilitation of prejudice" (lih. Ricoeur, 1982: 66-67, 76; 1991b: 273-274, 283).

${ }^{4}$ Sebetulnya Ricoeur sendiri sudah menyadari urutan distortif dan integratif ini ketika ia mengatakan sendiri: "two layers of ideology_ideology as distortion and as the legitimation of a system of order or power - the integrative function of ideology, the function of preserving an identity, remains" (lih. Ricoeur, 1986: 258).

\section{DAFTAR PUSTAKA}

Blundell, Boyd. 2010. Paul Ricoeur between Theology and Philosophy: Detour and Return. Bloomington and Indianapolis: Indiana University Press.

Dornisch, Loretta. 1989. “Ricoeur's Theory of Mimesis: Implications for Literature and Theology”. Literature \& Theology. Vol. 3, No. 3, (November 1989).

Hardiman, F. Budi. 2015. Seni Memahami: Hermeneutik dari Schleiermacher sampai Derrida. Yogyakarta: Kanisius.

. 1992/1993. "Kritik atas Patologi Modernitas dan [Post]Modernitas: Habermas dan Para Ahli Waris Nietzsche". Driyarkara, Th. XIX, No. 2.

Kaplan, David M. 2003. Ricoeur's Critical Theory. New York: State University of New York Press. 
Ricoeur, Paul. 1966. Freedom and Nature: The Voluntary and the Involuntary. Trans. Erazim V. Kohak. Evanston Illinois: Northwestern University Press.

. 1967. Husserl: An Analysis of His Phenomenology. Trans. Edward G. Ballard and Lester E. Embree. Evanston: Northwestern University Press.

. 1969. The Symbolism of Evil. Trans. Emerson Buchanan. Boston: Beacon Press. . 1970. Freud and Philosophy: An Essay on Interpretation. Trans. Denis Savage. New Haven: Yale University Press.

. 1974. The Conflict of Interpretations: Essays in Hermeneutics. Ed. Don Ihde. Evanston: Northwestern University Press.

. 1982. Hermeneutics and the Human Sciences: Essays on Language, Action and Interpretation. Ed. John B. Thompson. Cambridge: Cambridge University Press.

. 1986a. Fallible Man. Trans. Charles A. Kelbley, Rev. Ed. New York: Fordham University Press.

. 1986b. Lectures on Ideology and Utopia. Ed. George H. Taylor. New York: Columbia University Press.

. 1988. Time and Narrative. Vol. 3. Trans. Kathleen Blamey and David Pellauer. Chicago dan London: The University of Chicago Press.

. 1991a. A Ricoeur Reader: Reflection and Imagination. Ed. Mario J. Valdes. Toronto dan Buffalo: University of Toronto Press.

. 1991b. From Text to Action: Essays in Hermeneutics. II. Trans. Kathleen Blamey and

John B. Thompson. Evanston, Illinois: Northwestern University Press.

. 1992. Oneself as Another. Trans. by Kathleen Blamey. Chicago and London: The University of Chicago Press.

. 1994. "Responsibility and Fragility: An Ethical Reflection". Religious Traditions: A Journal in the Study of Religion. (25 Juli 1994).

. 1995. Figuring The Sacred: Religion, Narrative, and Imagination, trans. David Pellauer and ed. Mark I. Wallace, Minneapolis: Fortress Press.

Simon, John C. 2016. “Hermeneutik Paul Ricoeur dan Tugas Emansipasi”. Doctoral dissertation of Theology. Yogyakarta: Universitas Kristen Duta Wacana.

Singgih, E.G. 2004a. Berteologi dalam Konteks: Pemikiran-Pemikiran Mengenai Kontekstualisasi Teologi di Indonesia. Jakarta dan Yogyakarta: BPK Gunung Mulia dan Kanisius. 
Singgih, E.G. 2004b. Iman dan Politik dalam Era Reformasi di Indonesia. Jakarta: BPK Gunung Mulia.

_ 2004. Iman dan Politik dalam Era Reformasi di Indonesia. Jakarta: BPK Gunung Mulia.

Stiver, Dan R. 2001. Theology after Ricoeur: New Directions in Hermeneutical Theology. Louisville: Westminster John Knox Press. 